\title{
Can the benefits of cannabinoid receptor stimulation on neuroinflammation, neurogenesis and memory during normal aging be useful in AD prevention?
}

Yannick Marchalant ${ }^{1,2^{*}}$, Kevin Baranger ${ }^{1,2}$, Gary L Wenk ${ }^{3}$, Michel Khrestchatisky ${ }^{1,2}$ and Santiago Rivera ${ }^{1,2}$

\begin{abstract}
Background: Alzheimer's disease has become a growing socio-economical concern in developing countries where increased life expectancy is leading to large aged populations. While curing Alzheimer's disease or stopping its progression does not appear within reach in a foreseeable future, new therapies capable of delaying the pathogenesis would represent major breakthroughs.

Presentation of the hypothesis: The growing number of medical benefits of cannabinoids, such as their ability to regulate age-related processes like neuroinflammation, neurogenesis and memory, raise the question of their potential role as a preventive treatment of AD.

Testing the hypothesis: To test this hypothesis, epidemiological studies on long term, chronic cannabinoid users could enlighten us on the potential benefits of these compounds in normal and pathological ageing processes. Systematic pharmacological (and thus more mechanistic) investigations using animal models of Alzheimer's disease that have been developed would also allow a thorough investigation of the benefits of cannabinoid pharmacotherapy in the pathogenesis of Alzheimer's disease.

Implications of the hypothesis: The chronic administration of non-selective cannabinoids may delay the onset of cognitive deficits in AD patients; this will dramatically reduce the socio-economic burden of AD and improve the quality of life of the patients and their families.
\end{abstract}

Keywords: Alzheimer's disease, Ageing, cannabinoids, neuroinflammation, neurogenesis, prevention

\section{Background}

Alzheimer's disease (AD) is the most common neurodegenerative disease and accounts for the majority of diagnosed dementia after age 60. Currently available drugs only produce temporary relief from some cognitive symptoms without delaying, stopping or reversing the neuropathology. Due to poor efficacy of current treatments and the likely delay to implement future safe and efficacious treatments, there is an opportunity to develop preventive approaches based on currently available knowledge regarding the pathogenesis of AD. Neuroinflammation has attracted growing attention due to its

\footnotetext{
* Correspondence: yannick.marchalant@univ-amu.fr

${ }^{1}$ Aix-Marseille Univ., NICN, UMR 7259, 13344, Marseille, France

Full list of author information is available at the end of the article
}

slow progression and chronic nature, particularly during normal aging, as well as its involvement in various neurodegenerative diseases [1]. Neuroinflammation has thus been targeted by numerous pharmacological agents [1-4]. Elderly patients (65 years and older) treated with nonsteroidal anti-inflammatory drugs (NSAIDS) for 24 months exhibited a surprisingly lower prevalence of developing AD years later (follow up of 8 years, [5]). Subsequent clinical trials with NSAIDS were conducted on AD patients but failed to demonstrate significant beneficial effects [6]. Indeed, studies show that NSAIDS tend to lose efficacy in aged animals [7], which may account for the negative results of the clinical trials [6].

Most recent therapies have been designed and tested first in transgenic mice models and rarely take into

\section{C) Biomed Central}


account the ageing factor linked to AD development. As $95 \%$ of AD cases are non-familial and occur in the latter stages of life, basic knowledge on normal ageing processes and the way to delay them appear as a logical approach to tackle AD [8].

The endocannabinoid system has recently raised a great deal of interest in AD research, notably as a powerful modulator of neuronal activity (i.e. glutamatergic neurons) or inflammatory processes [9-11]. Cannabinoids already have numerous common uses as anti-emetics during cancer treatment or relief from inflammation-related pain [12]. Natural or synthetic cannabinoids exhibit variable specificity and selectivity for cannabinoid receptors [2]; this fact is particularly important in the light of the wellknown psychoactive effect of some of these compounds due to their actions on neuronal CB1 receptors [13]. Despite the challenge of targeting receptors that potentially disrupt learning and memory, neuroprotective approaches have been taken to circumvent those effects by targeting more specifically the CB2 receptor, by modulating the degradation pathway of endocannabinoids, or by using low, non-psychoactive doses of non-selective agonists of CB1/CB2 receptors [14-16]. Indeed, in exploring the potential of cannabinoids in a preventive approach, we have recently demonstrated that non-psychoactive doses of a non-specific cannabinoid agonist (WIN-55,212-2) can decrease chronic neuroinflammation, restore hippocampal neurogenesis and improve memory in aged rats [17-20].

Hence cannabinoids are endowed with unique proclivities that warrant their use in the prevention of ageassociated cognitive decline.

\section{Presentation of the hypothesis}

From the above, we postulate that modulation of the endocannabinoid system in recently diagnosed AD patients by daily administration of low-doses of cannabinoids could at minimum delay the disease progression. In the long run, a preventive approach aimed at the general ageing population may become appropriate.

\section{Testing the hypothesis}

Epidemiological studies have already been conducted on cannabis users, in particular in adolescents for the still controversial role of cannabinoids in the development of psychosis such as schizophrenia [21]. The popularity of cannabis among a significant number of people, notably in the 1970's, and the fact that some of these people still use cannabis chronically, could allow the identification of a cohort of chronic users who are currently over 60 years of age. If such a cohort could be constituted and cognitively tested, it would contribute to an evaluation of the effects of long term use of cannabinoids on brain ageing.

Further studies should be carried out on animals to address preclinical questions. These should involve chronic administration of different non-selective cannabinoids (e.g. WIN-55,212-2, cannabinol, $\Delta^{9}$-THC, HU210 , anandamide, or inhibitors of endocannabinoid degradation) in mouse models of AD. Indeed, mice have been genetically engineered to incorporate human mutations of genes encoding the amyloid precursor protein (APP) and presinilins (PS) linked to familial cases of $\mathrm{AD}$, and/or the hyperphosphorylation of Tau protein [22-26]. Despite their "artificial" nature, transgenic mice represent a very convenient model to test various hypotheses in young and aged animals with reasonable efficiency in terms of time and costs. Among mouse models, hallmarks of AD pathology can be reproduced (amyloid plaques and/or neurofibrillary tangles, often associated with neuroinflammation) with an onset and progression depending on the "aggressivity" or number of mutations carried by the animals. These models would provide an interesting array of experimental conditions to test our hypothesis and notably the effects of cannabinoids on:

- Neuroinflammatory markers, now commonly associated with the development of the disease, such as glial cell responses and their inflammation-related production of specific inflammatory markers. Modulators of both inflammatory responses and $\mathrm{APP} / \mathrm{A} \beta$ metabolism such as the metalloproteinases (ADAM10, ADAM-17, MMP-2, -9, -14 and -25) remain to be explored.

- The expression of APP and its catabolites $A \beta$ and sAPP $\alpha$, as representatives of the amyloidogenic and non-amyloidogenic pathways, respectively. It will be of particular interest to evaluate the ratio of intracellular vs extracellular $A \beta$, and $A \beta$ oligomers vs fibrils, considering the specificities of their toxicity.

- Tau protein hyperphosphorylation leading to formation of neurofibrillary tangles.

- Neurogenic processes that could slow or compensate ongoing neurodegeneration.

- Cognitive abilities tested using a variety of behavioral tasks.

\section{Implications of the hypothesis}

The complex nature of AD advocates for the use of a multimodal drug approach that could protect from the various processes underlying neurodegeneration and thus, at minimum, delay the pathological process. The expected benefit from a chronic treatment aimed at stimulating the endocannabinoid system is a delayed progression of AD: i.e. reduced inflammation, sustained potential for neurogenesis, reduced accumulation of $A \beta$, reduced hyperphosphorylation of Tau and delayed memory impairment. Such results could lead to new therapeutic strategies that target both the chronic inflammation and the decline in 
neurogenesis associated with both normal ageing and AD. Most importantly, delaying disease progression will significantly reduce the number of severely impaired $A D$ patients and thus reduce the growing socioeconomic burden associated with this disease.

\section{Acknowledgements}

GLW was supported by U.S. Public Health Service, RO1 AG030331 and RO1 AG037320.

International reintegration grant for the European Union (NGINFAD 20102014 for YM)

$A N R$ «TIMPAD » and «PREVENTAD » for SR MK

\section{Author details}

'Aix-Marseille Univ., NICN, UMR 7259, 13344, Marseille, France. ${ }^{2}$ CNRS, NICN, UMR 7259, 13344, Marseille, France. ${ }^{3}$ The Ohio State University, Psychology Department, Columbus, OH, USA.

\section{Authors' contributions}

YM, KB, GLW, MK and SR participated to the conception of the present hypothesis. All authors drafted and approved the final manuscript.

\section{Competing interests}

The authors declare that they have no competing interests.

Received: 8 December 2011 Accepted: 16 January 2012

Published: 16 January 2012

\section{References}

1. Akiyama H, Barger S, Barnum S, Bradt B, Bauer J, Cole GM, Cooper NR Eikelenboom P, Emmerling M, Fiebich BL, Finch CE, Frautschy S, Griffin WS, Hampel H, Hull M, Landreth G, Lue L, Mrak R, Mackenzie IR, McGeer PL, O'Banion MK, Pachter J, Pasinetti G, Plata-Salaman C, Rogers J, Rydel R, Shen Y, Streit W, Strohmeyer R, Tooyoma I, et al: Inflammation and Alzheimer's disease. Neurobiol aging 2000, 21:383-421.

2. Pertwee RG: Pharmacological actions of cannabinoids. Handbook of experimental pharmacology 2005, 1-51

3. Perry VH, Cunningham C, Holmes C: Systemic infections and inflammation affect chronic neurodegeneration. Nat rev Immunol 2007, 7:161-7.

4. Klegeris A, McGeer EG, McGeer PL: Therapeutic approaches to inflammation in neurodegenerative disease. Current opinion in neurology 2007, 20:351-7.

5. in $t^{\prime}$ Veld Ba, Ruitenberg a, Hofman a, Launer L, van Duijn CM, Stijnen T, Breteler MM, Stricker BH: Nonsteroidal antiinflammatory drugs and the risk of Alzheimer's disease. New Engl j med 2001, 345:1515-21.

6. Meinert CL, McCaffrey LD, Breitner JCS: Alzheimer's Disease Antiinflammatory Prevention Trial: design, methods, and baseline results. Alzheimers dement 2009, 5:93-104

7. Hauss-Wegrzyniak B, Vraniak P, Wenk GL: The effects of a novel NSAID on chronic neuroinflammation are age dependent. Neurobiol aging 1999, 20:305-13.

8. Britton GB, Rao KSJ: Cognitive aging and early diagnosis challenges in Alzheimer's disease. J Alzheimers dis: JAD 2011, 24(Suppl 2):153-9.

9. Németh $B$, Ledent $C$, Freund TF, Hájos N: CB1 receptor-dependent and -independent inhibition of excitatory postsynaptic currents in the hippocampus by WIN 55,212-2. Neuropharmacology 2008, 54:51-7.

10. Downer EJ: Cannabinoids and innate immunity: taking a toll on neuroinflammation. The Scientific World Journal 2011, 11:855-65.

11. Alger BE, Kim J: Supply and demand for endocannabinoids. Trends Neurosci 2011, 34

12. Mackie K: Cannabinoid receptors as therapeutic targets. Annu rev pharmacol toxicol 2006, 46:101-22.

13. Zanettini C, Panlilio LV, Alicki M, Goldberg SR, Haller J, Yasar S: Effects of endocannabinoid system modulation on cognitive and emotional behavior. Frontiers in behav neurosci 2011, 5:57.

14. Fowler CJ, Holt S, Nilsson O, Jonsson K-O, Tiger G, Jacobsson SOP: The endocannabinoid signaling system: pharmacological and therapeutic aspects. Pharmacol biochem be 2005, 81:248-62.
15. Ashton JC, Glass M: The Cannabinoid CB2 Receptor as a Target for Inflammation-Dependent Neurodegeneration. Curr Neuropharmacol 2007, 5:73-80.

16. Marchalant $Y$, Brothers HM, Wenk GL: Inflammation and aging: can endocannabinoids help? Biomed Pharmacother 2008, 62:212-217.

17. Marchalant Y, Brothers HM, Wenk GL: Cannabinoid agonist WIN-55,212-2 partially restores neurogenesis in the aged rat brain. Mol psych 2009, 14:1068-9.

18. Marchalant Y, Cerbai F, Brothers HM, Wenk GL: Cannabinoid receptor stimulation is anti-inflammatory and improves memory in old rats. Neurobiol Aging 2008, 29:1894-1901.

19. Marchalant Y, Rosi S, Wenk GL: Anti-inflammatory property of the cannabinoid agonist WIN-55212-2 in a rodent model of chronic brain inflammation. Neuroscience 2007, 144:1516-22

20. Marchalant Y, Brothers HM, Norman GJ, Karelina K, DeVries a C, Wenk GL: Cannabinoids attenuate the effects of aging upon neuroinflammation and neurogenesis. Neurobiol Dis 2009, 34:300-307.

21. Malone DT, Hill MN, Rubino T: Adolescent cannabis use and psychosis: epidemiology and neurodevelopmental models. Brit j pharmacol 2010, 160:511-22.

22. Morgan D, Gordon MN, Tan J, Wilcock D, Rojiani AM: Dynamic complexity of the microglial activation response in transgenic models of amyloid deposition: implications for Alzheimer therapeutics. J Neuropathol Exp Neurol 2005, 64:743-753.

23. McGowan E, Eriksen J, Hutton M: A decade of modeling Alzheimer's disease in transgenic mice. Trends Genet 2006, 22:281-9.

24. Morrissette Da, Parachikova A, Green KN, LaFerla FM: Relevance of transgenic mouse models to human Alzheimer disease. I biol chem 2009, 284:6033-7.

25. Oakley H, Cole SL, Logan S, Maus E, Shao P, Craft J, Guillozet-Bongaarts A, Ohno M, Disterhoft J, Van Eldik L, Berry R, Vassar R: Intraneuronal betaamyloid aggregates, neurodegeneration, and neuron loss in transgenic mice with five familial Alzheimer's disease mutations: potential factors in amyloid plaque formation. J Neurosci 2006, 26:10129-40.

26. Oddo S, Caccamo A, Shepherd JD, Murphy MP, Golde TE, Kayed R, Metherate R, Mattson MP, Akbari Y, LaFerla FM: Triple-Transgenic Model of Alzheimer's Disease with Plaques and Tangles Intracellular $A \beta$ and Synaptic Dysfunction. Neuron 2003, 39:409-421.

doi:10.1186/1742-2094-9-10

Cite this article as: Marchalant et al: Can the benefits of cannabinoid receptor stimulation on neuroinflammation, neurogenesis and memory during normal aging be useful in $A D$ prevention? Journal of Neuroinflammation 2012 9:10.

\section{Submit your next manuscript to BioMed Central and take full advantage of:}

- Convenient online submission

- Thorough peer review

- No space constraints or color figure charges

- Immediate publication on acceptance

- Inclusion in PubMed, CAS, Scopus and Google Scholar

- Research which is freely available for redistribution 